\title{
DESIGNATION OF GENDER ON ELECTRONIC EFL TEXTBOOK FOR SENIOR HIGH SCHOOL
}

\author{
Imam Santosa \\ Department of English Education, Sekolah Tinggi Keguruan dan Ilmu Pendidikan (STKIP) \\ Media Nusantara Citra, Indonesia \\ E-mail: imam_santosa@stkipmnc.ac.id
}

APA Citation: Santosa (2020). Designation of gender on electronic EFL textbook for senior high school. Indonesian EFL Journal, 6(2), 127-138. doi: 10.25134/ieflj.v6i2.3381.

\begin{abstract}
This study aims to examine gender representation in the electronic EFL textbook for senior high school. Content analysis will be utilized to examine gender representation in the electronic EFL textbook for senior high school entitles "Bahasa Inggris X" published by Puskurbuk. The study probes gender representation focusing on the designation of the character proposed by UNESCO. The designation of the gender representation in the textbook comprises 5 designations; first name, family relationship, other relationship, occupational status (agriculture, education, trade, small business, health, art and culture, and office) other status. The study later will reveal how the designation of the gender representation in the textbook. The comparison is $40 \%$ and $31 \%$. Unsurprisingly, the number considered as ungendered character is slightly lower in 29. The designation of the character in textbook is dominated by first name with 98 appearance for male and 82 for female character. Then, the category followed by occupation status, (68:60 character), other relationship (52:34), and family relationship category (34:20). The result concluded that male character dominated in all designation category strengthen the position of the male as dominant character. Additionally, the result of the study will give the insight on how gender representation exists as the basis to evaluate the construction of the textbook.
\end{abstract}

Keywords: gender; gender bias; gender representation; textbook.

\section{INTRODUCTION}

During these decades, the issue of gender bias has been frantically conferred in English Language learning. The concern of gender bias highlights how men and women are portrayed in learning, especially in learning English. Portrayals of gender bias can be discovered in the use of language in the classroom as well as in teaching materials used during the learning process. The disproportion of roles and representations between men and women depicted in teaching materials may not be in accordance with real life. Thus, learning English that occurs is expected to increase awareness of gender equality between men and women in the representation of teaching materials.

The issue of gender bias addresses the imbalance proportion on the daily basis. This issue, certainly, alter student perception toward gender equality. It could also create intolerable because of unjustified and unfair situation based on gender bias (Mille, 1992). Moreover, Mustapha discovered that gender bias shaped children development, as basically, gender bias is systemic injustice depiction that makes one gender, especially women marginalized (Mustapha, 2013). In addition, Johansson and Malmsjö explained that gender bias refers to a situation where one gender is treated unfairly compared to the other gender (2009). By looking at the explanation above, gender bias is an imbalance and injustice that occurs in men and women in the education system where one gender is marginalized compared to other genders because of the limited opportunities to get an equal education and portrayal.

In 2005, 2006, and 2007, United nation through UNESCO emphasised the importance of gender equality on catering education for both boys and girl. Later, it synthesized the framework to determine gender equality on the textbook (Brugeilles \& Cramer, 2009). The framework also determined the essential role of the textbook to promote gender equality. However, recent study on gender bias on the textbook. Zhao identified the inequality gender on the text embedding on the text (2019). Furthermore, Ali uncovered gender-bias on the Iranian EFL textbook focusing on its illustration (Dabbagh, 2016). On the top of that, Vahdatinejad examined linguistic sexism on the textbook. Later, the result revealed lack, unfair, and unbalance women exposure in the textbook (Vahdatinejad, 2017). Later, Fahrian, Alek and Wekke (2019) investigated gender representation in the EFL textbook used by Islamic school. The outcome exposed the 
unbalance and inequal proposition inside the textbook. The previous researches validate gender bias on the textbook.

The studies of gender variously conducted on over the world. In 2003, Ansary and Babii (2003) depicted the role of particular gender in the daily activity. The study focus on the sexist attitude and gender value in the textbook. However, the study focus only the visibility of sexism in the textbook without concerning the role of each gender in the text. Furthermore, other study conducted by Sulistyo (2013) conducted the study on focusing the visibility of gender bias in the textbook. the study hugely showed gender inequality in the textbook. based on the two previous study on the gender, the fixation is on the visibility of the gender bias in the textbook. In this study, the issues are not only focus on how gender bias portrayed in the textbook, but also how gender equality exists in the textbook. the study also uses the UNESCO guideline on promoting gender equality in the textbook.

Textbook, understandably, has major impact on delivering issues. Textbook bears important role on transmits a society's cultural capital to its youngest citizens at a particular moment (Brugeilles \& Cramer, 2009). Textbook, furthermore, prevailed as an agent of change. Hutchinson and Torres (1994) assumed that a good textbook, properly used, can administer an exquisite agent for effective and long-lasting change. Crawford (2019) urged that textbook, as powerful tool, manufactured to meet a particular cultural, economic or social goals. In addition, smith and Apple justified Agger critical theory of text on how social science textbook performed a political role as a consignment tool to reflects the interest of capitalism and patriarchy (Apple \& Christian-Smith, 2018).

As the undeniably important role of the textbook, it is relevant to reinvestigate the designation of gender on the textbook. The teachers need to recognize if the textbook considered as gender biased and to equip themselves to modify the application of textbook to ensure the student obtain equal opportunity for learning. In case of unawareness of the teacher on gender bias in the textbook, especially in the dialogue, will, may unconsciously hinder the speaking practice contingency for the underrepresented gender.

Recently the study of gender in the textbook variously conducted in several aspect of analysis. Ariyanto (2018) examined the portrayal of gender inequality in the textbook. it revealed that gender stereotype presented in the visual and verbal text. Furthermore, Emilia (2017) analysed the reading text in the textbook using Transitivity system of functional grammar. The study showed that that males were perpetually constructed as 'adventurous', 'risk taker', 'active', 'independent', and 'capable'. Meanwhile, the Processes also indicate that the females were shaped as more 'passive', 'expressive', 'nurturing', and 'unassertive'. Ahmad and Shah (2019) analysed the representation gender bias in the textbook utilizing Fairclough's threedimensional model. The result of the study showed that the textbook is designed to maintain male dominance in implicit as well as explicit ways. Meanwhile, Yang (2016) investigate visual representation in the textbook carrying gender. The result showed that binary notions of gender often remained intact in their normative forms there were also other forms of representation which challenged them. The latest development of the gender equality concluded that, still, far from ideal.

Furthermore, UNESCO have created the project to promoting gender equality in every aspect of life. The project manifested in the 20142021 action plan of gender equality. It shows the guideline to ensure gender equality perspective is reflected in all policies. In related with the issue of Promoting gender equality, UNESCO in sync with International Network for Research into Gendered Representations in Textbooks (Réseau international de recherche sur les representations sexuées dans les manuels scolaires - RIRRS), undertook the project of gender equality by utilizing textbook (Brugeilles \& Cramer, 2009). The project originated the framework to examine gender in-equality in the textbook. The framework incorporates characteristic of gender bias in the textbook. Those are Category, sex and age of the character, Designations, activities, attributes, interaction, and the location of the lesson. This study determined how those policies or action plan concluded in the reality. The study revealed how gender equality existed in the textbook. the revelation in this study would provide insight to the educator the gender issue in the textbook. it would lead the educator wisely use the textbook to promote gender equality.

\section{Gender bias}

Gender defined as a social and psychological dimension of sex (Huyck, 1999). Hyuck also determined the gender role as social ordinance or stereotypes associated with each sex; it may also be used to construe the extent to which a 
particular individual adhere with the social notion. Moreover, Scott (1986) explains the gender term used to discuss social organization about relationships between men and women. Furthermore, Scott in (Meyerowitz, 2008) conveyed that the word gender shift in meaning. Men or masculinity is depicted as Scott predicted, to the multiplicity strength, protection, independence, camaraderie, discipline, rivalry. In other hand, women or femininity represented weakness, fragility, helplessness, emotionality, passivity, domestication, nurturance, attractiveness, partnership, excess, and temptation. What is more, Stoller in (Geller \& Sved, 1997) referred gender as a particular balance of masculinity and femininity encountered in each person. The definition carried psychological or cultural rather than biological connotations. On the top of that, UNESCO defined gender as is pertinent to culture and the social division into "masculine" and "feminine". Gender therefore associated to the qualities, tastes, aptitudes, roles and responsibilities associated with men and women in a society. Definitions of masculine and feminine differ enormously exhibit their social origin considering every society establish its classification on the basis of its own criteria and principles. The notion of masculinity and femininity are not refined independently of each other but are commonly reliant. Accordingly, the word gender is not associated with the definition of sex carried by biological connotation but rather social, cultural and psychological connotation.

Unfair portrayals that tend to be biased between men and women in education still exist even though it is very hidden. Gender bias as explained by Raina (2017) is the difference in opportunities that men and women have in the education system which ultimately affects men and women in undergoing and completing education. In line with the previous explanation, Zittleman and Sadker (2002) explained that men and women receive different education even though they sit in the same class, read the same book, listen to the same teacher.

Gender bias, in fact, prevail in the several aspects of daily basis. Rovino and Rorong (2019) examined tinder application as semiotic analysis on its gender performance. The result revealed that although generally tinder user remained to conform to the traditional gender ideology that is masculine-centric and feminine-centric, the subversive gender performances that went against the traditionalist view on gender were also noticeably. On the other hand, Fay (1993) conducted an experiment on how women unfairly discriminated on requesting loan. The result widely held perception that women can encounter gender discrimination when requesting loan. Such discriminatory behaviour by loan officers may not be, and probably is not, intentional. Rather, the pervasiveness of the social construction of differential gender roles in western culture is such that it is more likely that discrimination is unconscious, and consequently more difficult to change.

Furthermore, Mustapa (2013) explained that gender bias can affect the quality of education because it can affect the development of children because basically gender bias is a systematic injustice of representation that makes one gender, especially women marginalized. In addition, Johansson and Malmsjö (2009) explained that gender bias refers to a situation where one gender is treated unfairly compared to the other gender.

Moreover, Macnell, Driscoll and Hunt (2015) administered the experiment on how student perceive the rate of teacher based on gender in online classroom. The result delivered that student tends to rate male teacher higher than female teacher. The students rated the male identity significantly higher than the female identity, regardless of the instructor's actual gender, demonstrating gender bias. Given the vital role that student ratings play in academic career trajectories, this finding warrants considerable attention. The findings and the result inline the result by Olafsdottir (2018). Olafsdottir discovered that the discrepancy between student evaluation of teaching for male and female faculty, using random-effects ordered logit regressions. I find that female faculty receive lower evaluations than male faculty in a simple model. In a model linking each of the covariates with gender I find an even greater gender bias for full-time faculty, while female part-time instructors receive higher student evaluation of teaching than their male counterparts.

Gender bias in EFL classroom can be obstacle to develop student ability in learning. Hassaskhah \& Zamir (2013) examine studentteacher interaction and student-student interaction focusing on gender theory. The result uncovered that there were significant differences in the quantity and quality of the interaction for females and males in almost all categories of interaction. The study also revealed that the presence of any negative barrier such as gender bias is likely to hinder development. Minasyan (2017) conducted 
an investigation how teachers and students position themselves within different discourses in EFL classroom interaction. The result emphasises 4 point on gender issue. Those are (a) teachers are biased in favour of boys, especially with respect to giving them more attention; (b) male students demand more teacher attention and more instructions from the teacher than their female peers; (c) female students are more likely to receive praise and positive comments, whereas male students are reprimanded by the teacher; (d) male students are more active in class participation, by taking more turns, volunteering and calling out. So, by looking at the explanation above, gender bias is an imbalance and injustice that occurs in men and women in the education system where one gender is marginalized compared to other genders because of the limited opportunities to get an equal education and portrayal.

In the term of professionalism in the education, gender bias unbelievably existed. Jan Sauermann, Mengel and Zolits (2019) revealed that particular gender would obtain lower score than other in the teaching evaluation. Moreover, the study also uncovered the slow progress of particular gender in the career path. In the other hand, the study conducted by Helmer, Schottdorf, Neef, \& Battaglia, (2017) showed that women are underrepresented in the peer-review process, that editors of both genders operate with substantial same-gender preference (homophily), and that the mechanisms of this homophily are genderdependent.

\section{Gender bias in the textbook}

Gender bias manifested in EFL material especially textbook. Amini (2012) investigated gender bias in Iranian textbook. The focus of the study was the visibility (frequency and nature) of the two genders across five sections containing omission, firstness, masculine generic constructions, occupations and activities in two of the Iranian EFL textbooks currently practiced at the high school level. Those categories were examined in both text and illustration. The result conclude that every category examined was reveal gender bias. The result showed over posed male characters both text and illustration in frequency and order of occurrence, occupation, stereotypical activities, and the linguistic manifestation of masculine generic referents.

Parham (2013) The present study explored the representation of gender in conversations, illustrations and graphic design of the cover in nine packages designed to teach English to young children for evidence of bias. The study investigated the gender bias on three different point. The first was conversation. The conversation was divided into 3 main variables to be analysed of gender representation; number of participants, and lastly, the number of turns that males and females take in a conversation. Next, second point was how gender was represented in illustrations. Two variables were inspected; the appearance of each gender and the prominence of the character. The last point was the representation of gender in the cover design of the books apart to the number of male and female characters present. The findings of this study exposed that conversations in EFL books for children have moved toward a more egalitarian representation of females and males, and surprisingly females have achieved equitable visibility in conversations. The results, yet, further exhibit the under-representation of female characters in illustrations of the textbooks studied.

In the other hand, Johansson \& Malmsjo (2009) differently investigated gender representation focusing on the dialogue in the textbook. The focus of the studied rely on 4 different typologies of the dialogue within the textbook; Initiating a dialogue Turns taken, Number of characters and Number of words used. The result, again, conform the over-presentation on one particular gender. In the initiating the dialogue, female turned to be dominant appearance in the dialogue. Next, as in the turn taken typology., the overall appearance of each gender indicated that, again, women gained more presentation than man. Then, in the typology of number of character representation in the textbook, male emerged as over-representation character. And the last was word used. In this typology, male outnumbered female. The result, again, indicates that gender bias, still, lie on the textbook though the domination of the gender in this study was female. Broadly speaking, three previous study concluded that gender bias, unfortunately, still, exist in the textbook. The portrayal gender bias emerged in both text and illustration.

\section{The role of textbook}

According to UNESCO, Textbook: define as the core learning medium composed of text and/or images created to deliver about a particular educational outcome; traditionally a printed and bound book including illustrations and instructions for aiding chain of learning activities. (UNESCO, 2005). Textbook greatly contribute in learning as the tools of delivering knowledge. 
Besides, textbook enact as an important aspect in children nurturing and educating by disseminate the epitome of social behaviour, norms and values of society (Brugeilles \& Cramer, 2009). Hutchinson and Torres (1994) assumed that a good textbook, properly used, can administer an exquisite agent for effective and long-lasting change. Crawford (2019) urged that textbook, as powerful tool, manufactured to meet a particular cultural, economic or social goals. In addition, smith and Apple justified Agger critical theory of text on how social science textbook performed a political role as a consignment tool to reflects the interest of capitalism and patriarchy (Apple \& Christian-Smith, 2018).

Moreover, Lau et al (2018) justified the importance of textbook in the learning process. The textbook delivered the flexibility in the teaching and learning on digital situation. The argument believe that the role is textbook, not only, as mere transmitting knowledge, but also as a tool to deliver the idea, culture and particular view. Edge (1993) in Tabassum (2018) pointed out the benefit of textbook as attractive, reliable and user friendly. Later, UNESCO further note that Textbook as the vehicle of values and models of social behaviour through the representations that textbook contained (Brugeilles \& Cramer, 2009).

\section{Textbook evaluation}

Textbook carries both positive and negative aspect on it based on the way we used it and how it delivered. Cunningsworth (1995) argued the importance of textbook evaluation as a basis to get the best of the textbook and get rid of the weakness. Furthermore, Ahmadi and Ali (2016) determined that textbook evaluation would create an opportunity to the teacher to reflect their perception of the strength and the weakness of the textbook. Lopez (2016) believe that textbook evaluation would create adjustment of the textbook in the future. Bogoleva (2016) concluded that textbook evaluation could be one of instrument to identify both pedagogical and linguistic need for the student and the teacher.

Gender equality framework by UNESCO

Promoting gender equality, UNESCO formulated a methodological guidance for textbook. The method utilized the framework instrument to evaluate the material contained gender bias in the textbook (Brugeilles \& Cramer, 2009). UNESCO believed that people should get equal opportunity in the society, regardless the gender.

The guidance has two fundamental objectives. The intentions here is therefore to consider the textbook's comprehensive environment and all the parties entangled and to explore the possibilities of the textbook as a vehicle for gender equality. In this context, textbooks are compelling leverage of social change in inseminator universal values (Brugeilles \& Cramer, 2009). The first objective is to display the existence of gender equality in the textbook. Next aim is to give the party involved in the creating textbook a suggestion to scrutinize the textbook or the suggestion to use the textbook critically.

The studies (Johansson \& Malmsjo, 2009; Parham, 2013; Amini, 2011; Brugeiles and Cramer, 2009) indicated that gender bias can be detected by two may feature; text and illustration. The text may contain text, dialogue, instruction, task and activity in the textbook and the illustration may contain the image inside the textbook.

Furthermore, Based on International Network for Research into Gendered Representations in Textbooks (Réseau international de recherche sur les représentations sexuées dans les manuels scolaires - RIRRS), gender bias in the textbook occurred in the six particular category (Brugeilles \& Cramer, 2009). The first category is category, sex and age of the character. This category concerns the representation of the character based on its biological connotation of gender such as man, boys, woman, or girls. Next category is designation. Designation is the situation that being given to the character in the text. The designation category narrowed into first name/surname or title family relationship (mother, uncle, etc.) Other relationship (friend, neighbour, etc.) Occupational status (occupation, political or religious office). This category of designation can be decided into 7 group. Agriculture: farmer, farm manager related job, Education: primary-school teacher, secondaryschool teacher; Trade: shopkeeper, salesman/saleswoman, bookseller; Health: doctor, pharmacist; Art, culture, science, media: artist, engineer, journalist; and Office work: office worker, secretary, librarian. Then beside previous category is other status (customer, traveller, etc.), another category is activities.

The activities is the action that being situated by the character such as school activity, occupational activity, formal or non-formal, domestic activity, buying activity, $\bullet$ care or caring activity, leisure, recreational or sports activity, social activity, routine personal activity (washing, eating), negative activity (making a mistake, 


\section{Imam Santosa}

Designation of gender on electronic EFL textbook for senior high school

breaking something, doing something inappropriate, causing problems), and successful activity. Next category is attribute. Attribute is defined as the attribute attached on the character such as school materials, occupational equipment or item, domestic item, money, food, leisure, recreational or sports equipment or item, physical characteristic, and psychological characteristic. Next category is interaction. Interaction is the situation involving character in the textbook such as, Occupational interaction, School interaction, Cooperative interaction (acting together, helping each other), Affective interaction (expressing affection, cuddling), Social interaction (talking, celebrating, inviting, sharing), and Violent interaction (quarrelling). And the last category is the position in the lesson whether the in the lesson or exercise.

Based on the discussion above, the reinvestigation concerning gender bias in EFL textbook for senior high school is needed. Senior high school student needs to be aware with the issue of gender equality. Thus, this study aims to examine gender representation in the electronic EFL textbook for senior high school.

\section{METHOD}

The purpose of the study is to examine gender representation in the electronic EFL textbook for senior high school. Content analysis was utilized to examine gender representation in the electronic EFL textbook for senior high school. Content analysis is described as the method to illustrate and calculate phenomena (Shelley \& Krippendorff, 1984) . It is also recognized as a method of analysing documents. Content analysis allows the researcher to assess theoretical issues to embellish understanding of the data. Through content analysis, it is possible to clarify words into fewer content related categories. It is inferred that when classified into the same categories, words, phrases and the like share the same meaning (Cavanagh, 1997). The aim is to attain a condensed and broad description of the phenomenon, and the outcome of the analysis is concepts or categories describing the phenomenon.

EFL textbook senior high school entitled "Bahasa Inggris X" was analysed to examine gender representation. In the grade ten, or the first grade of senior high school, the student faces different view of the classroom situation. The awareness of gender equality, showed in the gender representation, may lead how student react. As proposed in the guidance of the gender equality (Brugeilles \& Cramer, 2009), two main part of the textbook carry gender representation; text and illustration, as the limit of this study is focusing on the text not illustration. In order to analyse the data, this study tracked the procedure by UNESCO to analyse the gender representation in the text book (Brugeilles \& Cramer, 2009). The procedure started by selecting characteristics and compiling lists of details. The characteristics can be divided by several categories - sex, age, designation, actions, attributes, relations with other characters, position in chapter. In this study, the limitation is in 2 first categories; categories sex, age and designation. The designation consists of name/surname or title family relationship (mother, uncle, etc.) Other relationship (friend, neighbour, etc.) Occupational status (occupation, political or religious office). Thenceforth, the category be recorded in the grids inventory character designed by UNESCO. The grid focused on the text. Figure 1 showed the grid on text. Later the grids were connected with the grid analysis focusing on designation. And the last procedure was the summary table was analysed and an assessment made of parity and gendered representations. As Cramer and Brugeilles mention, the purpose of the assessment has 2 different angles, as in designing textbook and evaluating textbook. This study took the second angle. 


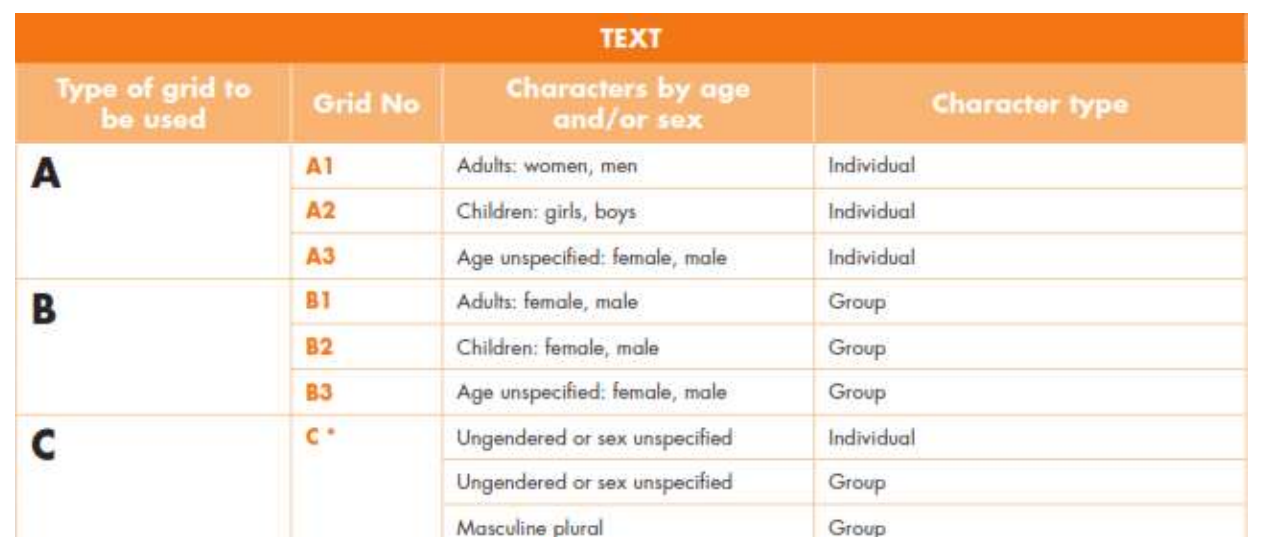

\section{RESULTS AND DISCUSSION}

Based on the analysis of the book, the result of the analysis is presented below.

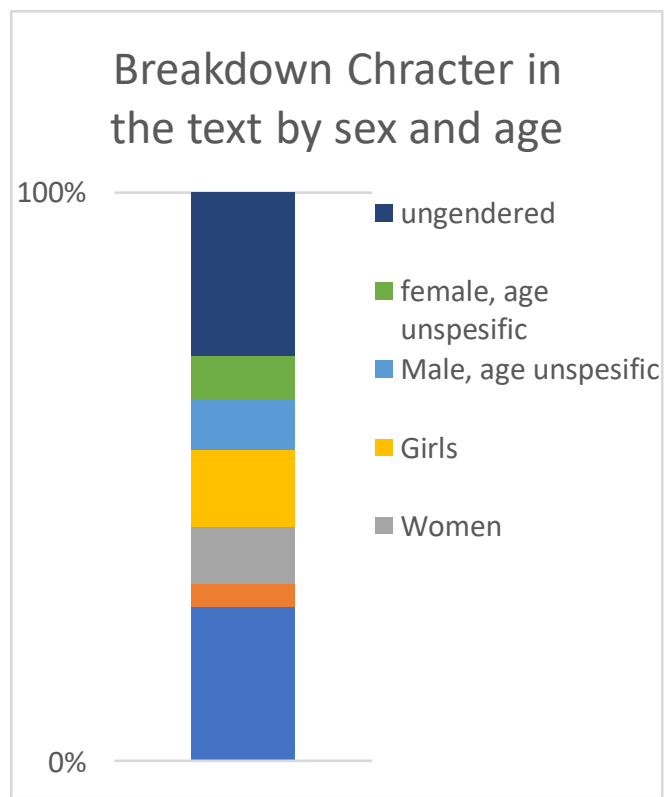

Figure 1. Breakdown character in the text by sex and age

The chart in the figure 1 suggested that, the characters designation by age and sex was in tight number differences. In total male outnumbered other categories with $40 \%$. The expansion of male character from the entire textbook, chapter 1-15, is greatly significant, only in the first chapter, entitled "let me introduce myself", the number of male characters was lower than female character. The rest chapter was dominated by male character. And the female character appearance concluded in $31 \%$. Surprisingly, ungendered character lied in $29 \%$. Adult male character substantially overrepresented, $27 \%$ comparing with women in the number only $10 \%$. Besides, girls outnumbered women, $13 \%$.

Based on data calculation, the male character overrepresented than other character. The domination of the male character conveyed that there is no gender equality in the textbook. The result is in line with previous study that indicate one of particular gender dominated in the textbook (Brugeilles \& Cramer, 2009; Fahriany et al., 2019; Johansson \& Malmsjö Bachelder, 2009; Parham, 2013). Besides, the figure, also, concluded that the female role model as an adult are rare only $10 \%$ from the total appearance which lead girl's pupil got less for identification and projection. This result is in line with the research of The International Network for Research into Gendered Representations in Textbooks in (Brugeilles \& Cramer, 2009). However, the significant number of ungendered representations demonstrated the intention promoting gender equality. 


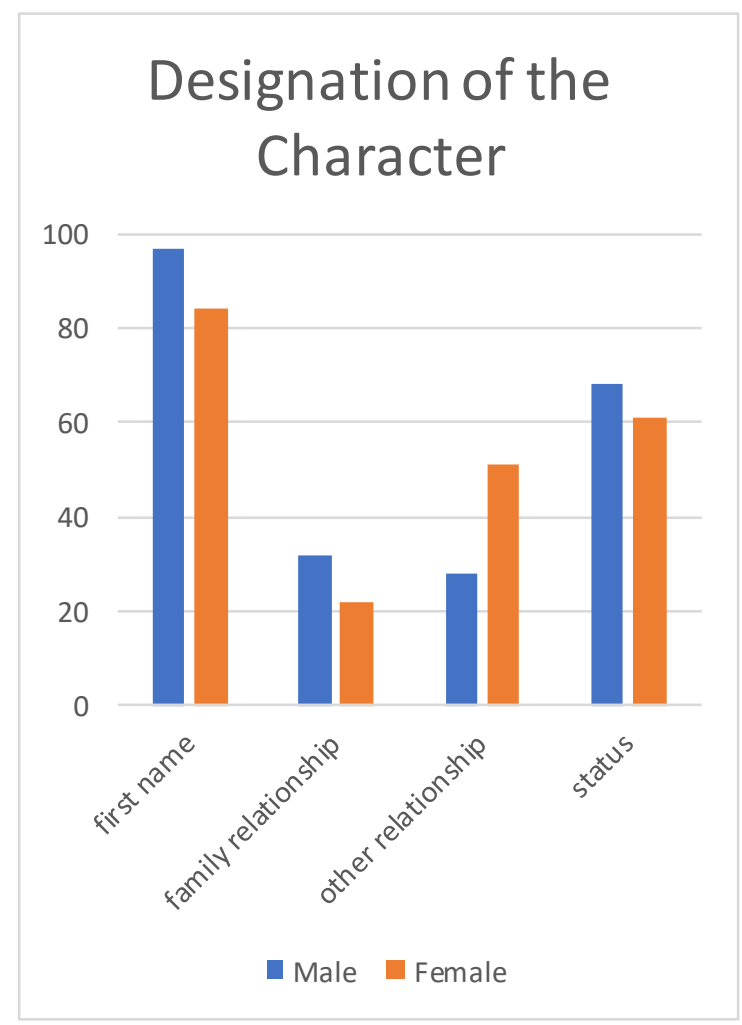

Figure 2. Designation of the character

The bar chart illustrates the number appearance of male and female character in the English textbook for senior high school. It can be seen that, Overall, male characters get more proportion than female character. The number both male and female character relatively high in the category of first name. The number reach 98 appearance on male and 82 . However, still, the male character outnumbers female character. In the family category, the number of character portrayal is, somewhat, the lowest among other. The number of male characters is 32 and 24 for female character. In the other relationship category, unusually, the number of female character overrepresented than male character with 52 to 24 appearance. However, the last category strengthens the domination of male character in the textbook. In the status category, male character exceeds female character on 68 appearances to 60 .

Based on the result, 4 out of 5 forms of designation male character exceeds the female characters. Women dominated in the other relationship which portrays the relationship of friend, neighbour. This result comes from the first chapter that put the female character as main characters in the dialogue between friend on the school situation and the naming character in the exercise as presented in Figure 3.

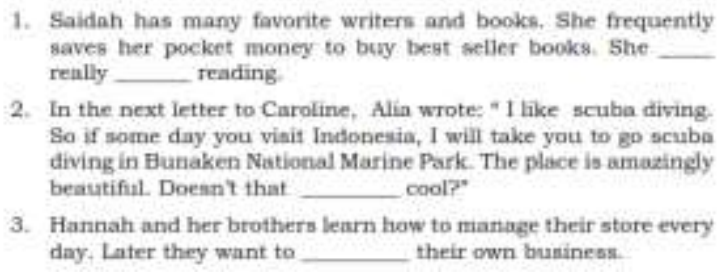

Figure 3. Examples of the use of name

The use of name Saidah, Alia and Hannah dominated the appearance of female character in this chapter. Besides the female character representation in the family relation ship status occurs mostly as a mother and sister. The result aligns as the research by UNESCO (Brugeilles \& Cramer, 2009).

The next chart displays the status attaching the character in the textbook. As presented in the figure 4 , the status of the character based its job 
can be divided into agriculture, trade, small business, education, Art, culture science and media, office worker and other status. The chart indicates that three occupational status dominate; education, Art, culture science and media and office worker. The distribution is varying according to the character's gender. In the education which includes teacher, student, headmasters and other related educational job, female relatively dominates the manifestation of education job with 33 appearance comparing to male with only 10 appearances.

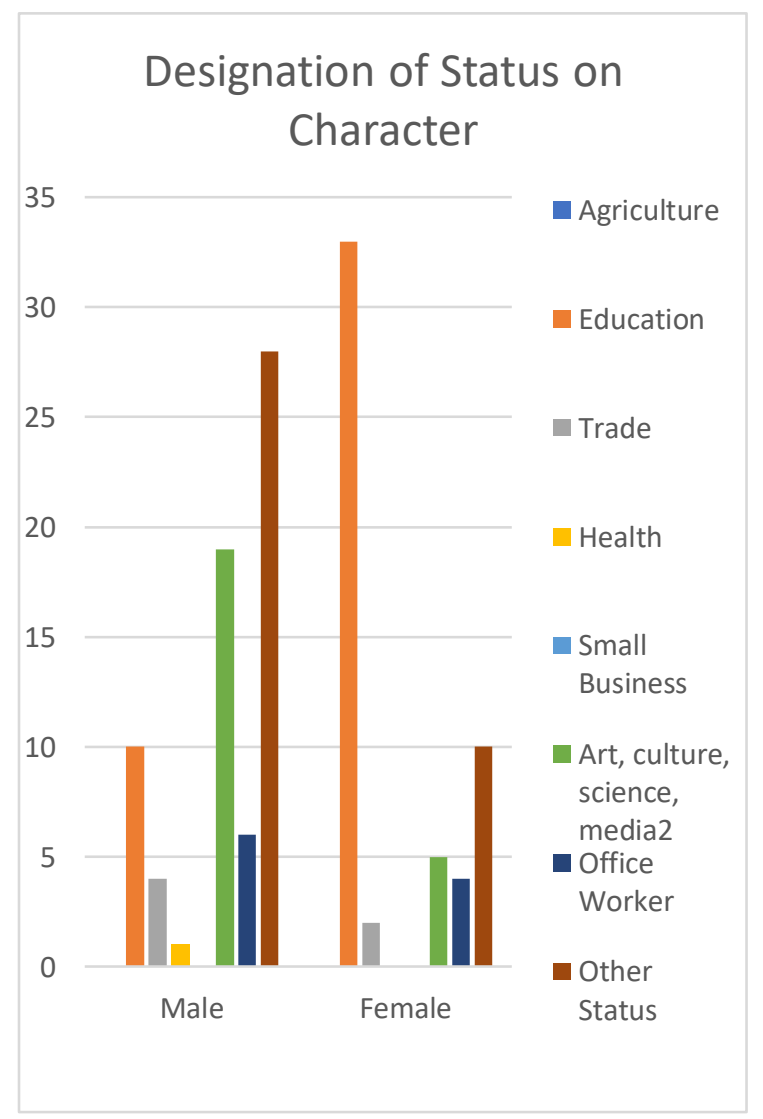

Figure 4. Designation of status on character

The domination of female character in this category comes from the status of student that lies on the female character in the dialogue and text presented in the first chapter. It can be inferred that the importance of women to get education is being portrayed in the textbook. The result is different by UNESCO research on gendered representation on math book that showed the representation of female character in the education category was low and represented the unimportant of education for female. However, even though the display of male character in this category is low, the status is significant. The male characters described as significant character like a student, teacher or headmasters. This outcome is related with the research by UNESCO that Male character tend to have significant role in society representation (Brugeilles \& Cramer, 2009). Other dominated category in occupational status is other status. Other status defined as the job that not include in the previous category. The uncategorized jobs appear in the textbook are army related job, government related job, and crime related job. As presented in figure 5, the male character extremely outnumbers female character. Unfortunately, the description of this job like thief, police, army, robber is associated with male character. Those jobs, often, associated with strength, brute force and masculinity. It is inline with the argument of Scott in (Emilia et al., 2017; Meyerowitz, 2008) that male represent multiplicity strength, protection, independence, camaraderie, discipline, rivalry. However, the representation of strength also comes from the female character.; Cut Nyak Dien. And the third dominated status is Art, media, science and culture. In this category, the male immensely exceeds female character. The comparison is 19 and 5 appearances. The quote of the famous 


\section{Imam Santosa}

Designation of gender on electronic EFL textbook for senior high school

person in the end of each chapter mostly comes from male character.

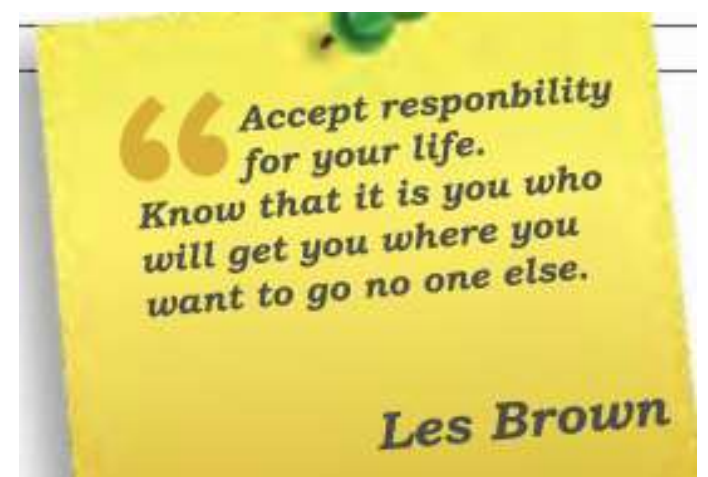

Figure 5. Examples of famous person quote

The female character emerges once which shows quote from Oprah Winfrey. This number indicates that male tend to be positioned as an idol and important figure. The result is in line with the study by (Johansson \& Malmsjö Bachelder, 2009). This result is also similar in the office category. The appearance of the male character and female character existed in the next representation, office work, is similar with the previous category. The male extendedly appears in this category. The male character is not only dominant in the appearance but also in the position of the job. The position of the male character in the textbook is portrayed higher than female character. The male character described as the manager or the leader but the female character is described as a staff as seen in Figure 6.

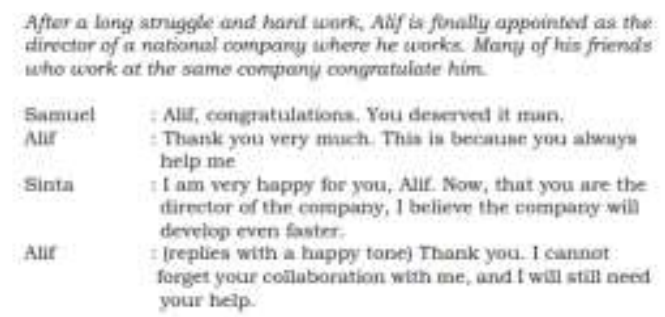

Figure 6. Examples of conversation in office

The one who being promoted and become director is male character, meanwhile the staff or the colleague is female. This result align with the research by (Ariyanto, 2018; Johansson \& Malmsjö Bachelder, 2009; Yang, 2016).

\section{CONCLUSION}

Based on the findings and discussion, it can be concluded that the presence of male character is outnumbered female character. The comparison is $40 \%$ and $31 \%$. The domination of the male character conveyed that there is no gender equality in the textbook. Furthermore, unsurprisingly, the number considered as ungendered character is slightly lower in $29 \%$. The ungendered character proves that there is intention to promote gender equality. Besides, the designation of the character in textbook is dominated by first name with 98 appearances for male and 82 for female character. Then the category followed by occupation status, (68:60 character), other relationship (52:34), and family relationship category (34:20).

The result concluded that male character dominated in all designation category strengthen the position of the male as dominant character. As the last finding; the occupational status; that three occupational status dominate; education, Art, culture science and media and office worker. The distribution is varying according to the character's gender. The highest representation is in the education female manifest higher than male in this category, but it is dominated by the status of student. However, the importance of education for female is showed in this representation. Then, other status is dominated by men that represent the job such as army, thief, robber, police. The kinds of job are associated with masculinity carried by male character. In the office work status, male, also, outnumbers female category. Even though, there are slight numbers of female in this category. The position of male, still, is 
higher. In overall, male dominated gender representation in the EFL textbook for Senior high school.

\section{REFERENCES}

Ahmad, M., \& Shah, S. K. (2019). A critical discourse analysis of gender representations in the content of 5th grade english language textbook. International and Multidisciplinary Journal of Social Sciences, 8(1), 1-24. https://doi.org/10.17583/rimcis.2019.3989.

Ahmadi, A., \& Derakhshan, A. (2016). EFL teachers' perceptions towards textbook evaluation. Theory and Practice in Language Studies, 6(2), 260267.https://doi.org/10.17507/tpls.0602.06.

Amini, M., \& Birjandi, P. (2012). Gender bias in the Iranian high school EFL textbooks. English Language Teaching. 5(2), 134-147 https://doi.org/10.5539/elt.v5n2p134.

Ansary, H., \& Babaii, E. (2003). Subliminal sexism in current ESL/EFL Textbooks. The Asian EFL Journal, 5(1).

Apple, M. W., \& Christian-Smith, L. K. (2018). The politics of the textbook. In The Politics of the Textbook.

$1,1-21$ https://doi.org/10.4324/9781315021089-1

Ariyanto, S. (2018). A portrait of gender bias in the prescribed Indonesian ELT textbook for junior high school students. Sexuality \& Culture, 22(4), 1054-1076.

Bogolepova, S. (2016). Textbook Evaluation as a Means of Discovering Learners' and Teachers' Needs. Journal of Language and Education, 2(4), 14-23 https://doi.org/10.17323/24117390-2016-2-4-14-23.

Brugeilles, C. \& Cramer, S. (2009). Promoting gender equality through textbook. Paris, UNESCO.

Crawford, K. (2019). Researching the ideological and political role of the history textbook issues and methods. History Education Research Journal, 1(1), 55-62. https://doi.org/10.18546/herj.01.1.07.

Dabbagh, A. (2016). Gender representation under critical image analysis: The case of Iranian ELT textbooks. International Journal of English Language \& Translation Studies, 4(4), 39-52.

Emilia, E., Moecharam, N. Y., \& Syifa, I. L. (2017). Gender in EFL classroom: Transitivity analysis in English textbook for Indonesian students. Indonesian Journal of Applied Linguistics, 7(1), 206-214.

Fahriany, F., Alek, A., \& Wekke, I. S. (2019). Gender Representation in English Textbooks for Islamic Junior High School Students. Kafa`ah: Journal of Gender Studies, 8(2), 149-167 https://doi.org/10.15548/jk.v8i2.221.

Fay, M., \& Williams, L. (1993). Gender bias and the availability of business loans. Journal of Business Venturing, 8(4), 363-376 https://doi.org/10.1016/0883-9026(93)90005-P.
Geller, J. L., \& Sved, M. (1997). Gender shock: Exploding the myths of male and female. Psychiatric Services, 48(8), 1088-1089 https://doi.org/10.1176/ps.48.8.1088-a.

Hassaskhah, J., \& Roshan, Z. S. (2013). Gendered Teacher-Student Interactions in English Language Classrooms: A Case of Iranian College Context., Sage Open,3(3) https://doi.org/10.1177/2158244013502986.

Helmer, M., Schottdorf, M., Neef, A., \& Battaglia, D. (2017). Gender bias in scholarly peer review. ELife research magazine https://doi.org/10.7554/eLife.21718.

Hutchinson, T., \& Torres, E. (1994). The textbook as agent of change. ELT Journal, 48(4),315-328.

Huyck, M. H. (1999). Gender Roles and Gender Identity in Midlife. Life in the Middle,, 209232., Elsevier, Academic press https://doi.org/10.1016/b978-0127572307/50030-4.

Johansson, S., \& Malmsjö Bachelder, K. (2009). Gender bias in EFL textbook dialogues. Retrieved 10 May, 2020 from http://muep.mau.se/handle/2043/8217.

Lau, K. H., Lam, T., Kam, B. H., Nkhoma, M., Richardson, J., \& Thomas, S. (2018). The role of textbook learning resources in e-learning: A taxonomic study. Computers and Education, $118(2)$, $10-24$ https://doi.org/10.1016/j.compedu.2017.11.005.

López Medina, B. (2016). Developing a CLIL textbook evaluation checklist. Latin American Journal of Content \& Language Integrated Learning, https://doi.org/10.5294/laclil.2016.9.1.7.

MacNell, L., Driscoll, A., \& Hunt, A. N. (2015). What's in a name: Exposing gender bias in student ratings of teaching. Innovative Higher Education,40, 291-303 https://doi.org/10 .1007/s10755-014-9313-4.

Mengel, F., Sauermann, J., \& Zölitz, U. (2019). Gender bias in teaching evaluations. Journal of the European Economic Association, 17(2), 535-566 https://doi.org/10.1093/jeea/jvx057.

Meyerowitz, J. (2008). A History of "Gender." The American Historical Review, 113(5), 1346-1356, https://doi.org/10.1086/ahr.113.5.1346.

Mille, K. W. (1992). Feminist critique of language: A reader. Women's Studies International Forum, 15(1), 146-147 https://doi.org/10.1016/02775395(92)90050-6.

Minasyan, S. (2017). Gendered patterns in teacherstudent interaction in EFL classroom: The Greek context. Journal of Language and Education, 3(3), 89-98 https://doi.org/10.17323/24117390-2017-3-3-89-98.

Mustapha, A. S. (2013). Gender and Language Education Research: A Review. Journal of Language Teaching and Research, 4(3), 454-463 https://doi.org/10.4304/jltr.4.3.454-463. 


\section{Imam Santosa}

Designation of gender on electronic EFL textbook for senior high school

Ólafsdóttir, K. (2018). Gender bias in student evaluation of teaching among undergraduate business students. Tímarit Um Viðskipti $O g$ Efnahagsmál. 15(1), 75-86 https:// doi.org/10.24122/tve.a.2018.15.1.4.

Parham, F. (2013). Gender representation in children's EFL textbooks. Theory and Practice in Language Studies, 3(9), 1667- 1679 https://doi.org/10.4304/tpls.3.9.1674-1679.

Raina, S. (2017). Gender Bias in Education. The SAGE Encyclopedia of Psychology and Gender, 01, 37-47. https://doi.org/10.4135/9781483384269.n209.

Rovino, D., \& Rorong, M. J. (2019). Gender Performance Discourse On Tinder Profile Pictures In London, Uk-A Social Semiotics Study. Bricolage: Jurnal Magister Ilmu Komunikasi 6(1), 17-33.

Scott, J. W. (1986). Gender: A useful category of historical analysis author. The American Historical Review.

Shelley, M., \& Krippendorff, K. (1984). Content analysis: An introduction to its methodology. Journal of the American Statistical Association. Journal of the American Statistical Association, 79(385), 240240.https://doi.org/10.2307/2288384.

Tabassum, A. (2018). Evaluation of the higher secondary textbook "English For Today" from CLT perspective. Dhaka, BRAC University.

UNESCO. (2005). A comprehensive strategy for textbooks and learning materials. Paris, UNESCO.

Vahdatinejad, S. (2017). Linguistic sexism in the Iranian high school EFL textbooks. PEOPLE: International Journal of Social Sciences, 3(2), 746-761. https://doi.org/10.20319/pijss.2017.32.746761.

Yang, C. C. R. (2016). Are males and females still portrayed stereotypically? Visual analyses of gender in two Hong Kong primary English Language textbook series. Gender and Education, 28(5), 674-692.

Zhao, J., Wang, T., Yatskar, M., Cotterell, R., Ordonez, V., \& Chang, K.-W. (2019). Gender Bias in contextualized word embeddings. Proceedings of the 2019 Conference of the North American Chapter of the Association for Computational Linguistics: Human Language Technologies, 629-634. https://doi.org/10.18653/v1/n19-1064.

Zittleman, K., \& Sadker, D. (2002). Gender bias in teacher education texts: New (and old) lessons. Journal of Teacher Education, 53(2), 168-180. https://doi.org/10.1177/0022487102053002008. 